\title{
Condições microclimáticas em cultivo de café conilon a pleno sol e arborizado com nogueira macadâmia
}

\author{
Microclimatic alterations in a conilon coffee crop grown shaded by macadamia nut tree
}

\author{
José Ricardo Macedo Pezzopane ${ }^{\mathrm{I}}$ Mariclei Maurílio Simões MarsettiI \\ Joabe Martins de SouzaII José Eduardo Macedo Pezzopane ${ }^{\text {III }}$
}

RESUMO

\begin{abstract}
Medições microclimáticas (radiação fotossinteticamente ativa - RFA, temperatura do ar, umidade relativa do ar e velocidade do vento) foram realizadas em um cultivo de café Conilon (Coffea canephora Pierre) cultivado a pleno sol e arborizado com nogueira macadâmia (Macadamia integrifolia Maiden \& Betche), no Município de São Mateus, Espírito Santo (ES) $\left(18^{\circ} 43^{\prime} \mathrm{S}\right.$; $39^{\circ} 54^{\prime} \mathrm{W}$; 39m), durante o período de setembro de 2008 a junho de 2009, com o objetivo de apresentar os efeitos do cultivo arborizado no microclima. Os resultados obtidos mostraram diferenças na transmissividade à RFA dentro do sistema arborizado em relação ao pleno sol, com variações de 18 a 88\% e de 17 a 87\% quando comparados em dois episódios de amostragem. A transmissividade média da RFA provocada pelas árvores de macadâmia variou de 65 a 59\% durante as duas épocas de amostragem. Com relação à velocidade do vento, ocorreu uma redução média de $72 \%$ em sua incidência no cultivo arborizado. As diferenças na transmissividade de radiação e na incidência de ventos proporcionaram diferentes regimes de temperatura do ar e umidade relativa do ar, com maior efeito sobre os valores diurnos e no ponto de amostragem próximo ao renque de macadâmias, em que a média da temperatura máxima do ar foi até $2,2^{\circ} \mathrm{C}$ inferior ao cultivo a pleno sol.
\end{abstract}

Palavras-chave: arborização, microclima, Coffea canephora, radiação fotossinteticamente ativa.

\section{ABSTRACT}

Microclimatic measurements (photosynthetically active radiation - PAR, temperature and relative humidity of air and wind speed) were made in a Conilon coffee crop (Coffea canephora Pierre), grown in two different conditions: shaded by macadamia nut trees (Macadamia integrifolia Maiden \& Betche) and unshaded. The experiment was carried out at Sâo

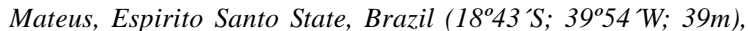
between September 2008 and June 2009, aiming to show the effects of shading crop system into the microclimate. The obtained results had inside shown differences in the transmission of PAR in the shaded crop, with variations of 18 to $88 \%$ and 17 to $87 \%$ when compared the two sampling episodes. The average transmission of PAR caused by macadamia nut trees varied of 65 to 59\% during the sampling episodes. The wind speed was reduced by $72 \%$ at the shaded crop. The differences in the transmission of PAR and the incidence of winds produced different values of temperature and relative humidity of the air with the greatest effect during day-light values period and at the sampling nearest point to macadamias nut trees, where the average maximum temperature was up to $2.2^{\circ} \mathrm{C}$ lower than the unshaded ones.

Key words: shaded, microclimate, Coffea canephora, photosynthetically active radiation.

\section{INTRODUÇÃO}

Para a cultura do cafeeiro, o uso da arborização visa a minimizar a exposição das plantas a riscos climáticos, como geadas, excessos de radiação solar, temperaturas elevadas e ventos excessivos, além de melhorar a fertilidade do solo e reduzir a lixiviação de nutrientes (VAAST et al., 2006). Proporciona ainda a agregação de uma fonte de renda extra para os cafeicultores (alimento, madeira, lenha, fibras, entre

IEMBRAPA Pecuária Sudeste, 13560-970, São Carlos, SP, Brasil. E-mail: jricardo@cppse.embrapa.br. Autor para correspondência. ${ }^{\text {IIC } C u r s o ~ d e ~ A g r o n o m i a, ~ C e n t r o ~ U n i v e r s i t a ́ r i o ~ N o r t e ~ d o ~ E s p i ́ r i t o ~ S a n t o, ~ U n i v e r s i d a d e ~ F e d e r a l ~ d o ~ E s p i ́ r i t o ~ S a n t o ~(U F E S), ~ S a ̃ o ~ M a t e u s, ~}$ ES, Brasil.

IIIDepartamento de Engenharia Florestal, Centro de Ciências Agrárias, UFES, Alegre, ES, Brasil. 
outros) e melhor aproveitamento da mão-de-obra durante o ano, nas diferentes atividades de manejo da lavoura, benefício de grande importância para a agricultura familiar.

Como estratégia de proteção de lavouras, a arborização de cafezais é uma técnica mais difundida em cultivos de café arábica (Coffea arabica) em comparação aos cultivos de café robusta ou conilon (Coffea canephora). No entanto, para ambas as espécies nas regiões tropicais da África, de onde são originados, seus cultivos são tradicionalmente realizados sob sombras de florestas nativas, com árvores raleadas ou não, ou mesmo com árvores introduzidas para tal fim. Um dos motivos da baixa adoção de arborização em lavouras de café conilon está relacionado com a característica de essa espécie ser originada de uma região caracterizada por temperaturas elevadas e estação seca moderada a acentuada (DAMATTA, 2004), o que se entende por maior adaptação a rigores climáticos.

A previsão de aquecimento global emitido pelo Painel Intergovernamental de Mudanças Climáticas (IPCC, 2007) acusa um aumento da temperatura e alteração no regime de chuvas das regiões tropicais. De acordo com FAZUOLI et al. (2007), o uso da arborização seria uma das técnicas de mitigação para o possível cenário de aquecimento global e seus efeitos na cafeicultura. Sob esse aspecto, a técnica se mostra promissora inclusive para o café conilon. Contudo, se faz necessária a realização de estudos microclimáticos para quantificar o efeito dos diferentes tipos de arborização na atenuação do microclima.

Vários autores observaram a variação de outros elementos meteorológicos em diversos tipos de cultivos de cafezais arborizados, nas diferentes regiões produtoras do Brasil e também em outros países. Destacam-se os trabalhos de BARRADAS \& FANJUL (1986) em um sistema agroflorestal de produção de café no México, CARAMORI et al. (1996) em um plantio de cafeeiros arborizados com bracatinga, em Londrina, Paraná (PR), PEZZOPANE et al. (2003) em um cafezal consorciado com coqueiro-anão e PEZZOPANE et al. (2007) em um cultivo consorciado de café arábica com banana Prata Anã, ambos em São Paulo.

Esses trabalhos evidenciaram as grandes diferenças microclimáticas relacionadas à velocidade do vento, a solo, a déficit de pressão de vapor entre os sistemas arborizados de produção de café e a cultivos a pleno sol, sendo constatada uma variabilidade temporal e espacial nos cultivos arborizados e que suas diferenças em relação a um cultivo a pleno sol dependerão do tipo de copa da árvore utilizada e da densidade do sombreamento.
O presente trabalho foi realizado com o objetivo de avaliar as condições microclimáticas em sistema de produção de café a pleno sol e arborizado com macadâmia no Município de São Mateus, Espírito Santo (ES).

\section{MATERIAL E MÉTODOS}

O experimento foi realizado no período de setembro de 2008 a junho de 2009, em uma área comercial de produção de café conilon (Coffea canephora Pierre) de aproximadamente quatro hectares, em terreno com declividade inferior a $10 \%$, cultivada a pleno sol e arborizada com nogueira macadâmia (Macadamia integrifolia Maiden \& Betche), no Município de São Mateus, ES (1843’S; 3954’W; 39m). A área do experimento é caracterizada por plantios de culturas perenes diversas e áreas de preservação. O clima da região é tropical com inverno seco, do tipo Aw (Köppen), com precipitação pluvial de $1.212 \mathrm{~mm}$ e temperatura média anual do ar de $23,8^{\circ} \mathrm{C}$.

No cultivo de café arborizado com macadâmia, implantado em 2001, as plantas de café estavam no espaçamento de $2,5 \mathrm{~m}$ entre linha e $1,5 \mathrm{~m}$ entre plantas, e a cada quatro linhas de café existia uma linha de macadâmia, com altura aproximada de cinco metros, com espaçamento de $12,5 \mathrm{~m}$ entre linha e 9,5m entre plantas (Figura 1). Essa configuração apresentava uma população de aproximadamente 2.200 plantas de café por ha e 120 árvores de macadâmia por ha. As linhas de café e macadâmia foram plantadas no sentido perpendicular à declividade do terreno, no sentido noroeste-sudeste. Nessa orientação, as linhas também se encontravam no sentido perpendicular ao sentido predominante dos ventos, que é norte-nordeste na região.

Em área adjacente ao talhão de café arborizado, existia um talhão de café cultivado em sistema a pleno sol (PS) na mesma condição de espaçamento, que serviu de padrão para comparação das medições realizadas na presente pesquisa. Nos dois cultivos, os tratos culturais foram realizados de acordo com as orientações técnicas para a região (FERRÃO et al., 2007).

Para facilitar a apresentação dos resultados e o entendimento do estudo realizado, foram estabelecidos alguns termos próprios no cultivo arborizado para a apresentação dos dados que estão ilustrados na figura 1. Cada linha de café entre dois renques de macadâmia foi assim nomeada: ARB 2,5 SO (linha de café com distância de 2,5m da linha de macadâmias voltada para o sentido cardeal sudoeste); ARB 5,0 SO (linha de café com distância de 5,0m da 


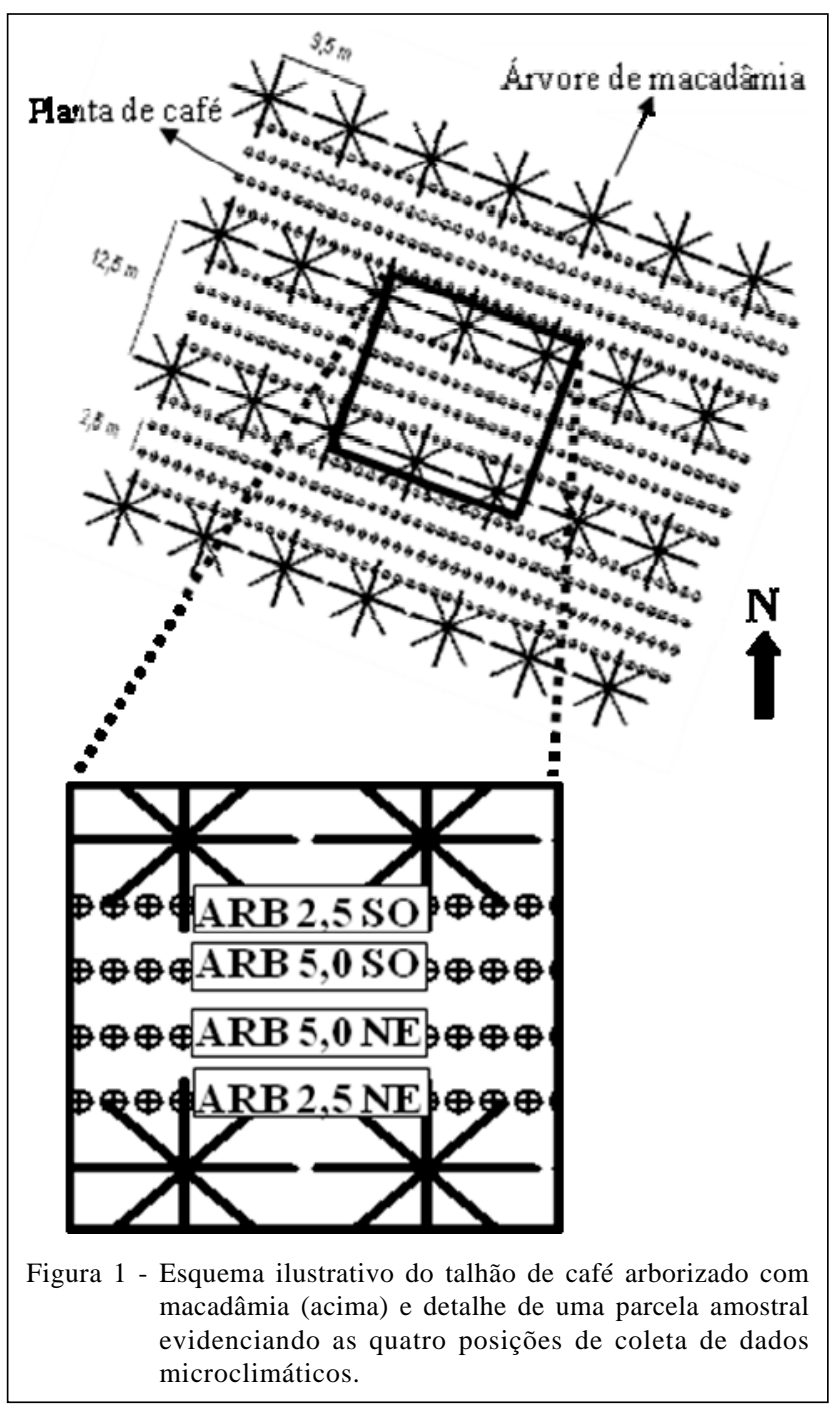

As amostragens da RFA no cultivo arborizado foram realizadas sobre cada uma das quatro linhas de café entre dois renques de macadâmia (ARB 2,5 SO; ARB 5,0 SO; ARB 5,0 NE e ARB 2,5 NE) em um total de quatro repetições, escolhidas ao acaso, dentro do talhão arborizado. Para compor a medida, em cada uma das repetições, mediu-se a RFA em três pontos situados no início, meio e final da parcela. As leituras foram realizadas no período da manhã (entre 9h30min e 10h30min), ao meio dia (entre $11 \mathrm{~h} 30 \mathrm{~min}$ e $12 \mathrm{~h} 30 \mathrm{~min}$ ) e no período da tarde (entre $13 \mathrm{~h} 30 \mathrm{~min}$ e $14 \mathrm{~h} 30 \mathrm{~min}$ ), visando a determinar a interceptação da RFA (relação entre a RFA sobre as plantas de café no cultivo arborizado e a RFA externa) ao longo do dia.

As medições microclimáticas consistiram também de coleta de dados de temperatura e umidade relativa do ar (Vaisala HMP50), com sensores instalados em abrigos multipratos, e velocidade do vento (MetOne 014A), realizada de maneira contínua sobre a copa das plantas de café (aproximadamente $20 \mathrm{~cm}$ sobre a parte superior do dossel), entre os meses de novembro de 2008 e julho de 2009, totalizando 223 dias de medidas, em dois pontos do sistema arborizado (ARB 2,5 SO e ARB 5,0 NE), além de um ponto do sistema pleno sol (PS), em área adjacente. Os sensores foram acoplados a um sistema automático de aquisição de dados (Campbell CR1000), programado para leituras a cada 20 segundos, médias a cada 15 minutos e obtenção dos valores médios e extremos diários. Para complementar a discussão sobre a
variação da umidade atmosférica, calcularam-se a

linha de macadâmias voltada para o sentido cardeal sudoeste); ARB 5,0 NE (linha de café com distância de 5,0m da linha de macadâmias voltada para o sentido cardeal nordeste); ARB 2,5 NE (linha de café com distância de 2,5m da linha de macadâmias voltada para o sentido cardeal nordeste).

Foram realizadas medidas de radiação fotossinteticamente ativa (RFA), em duas datas, 13/09/ 2008 e 10/02/2009, em condição ensolarada. No cultivo arborizado, a amostragem da RFA foi realizada com um sensor linear de 1m de comprimento (Licor Li-191) colocado horizontalmente sobre a copa dos cafeeiros, no sentido paralelo às linhas de plantas de café, efetuando-se uma medição instantânea, composta de 10 leituras em 30 segundos. Para medir a RFA livre da interferência das árvores de macadâmia (RFA externa), foi instalado um sensor em área externa ao experimento, cuja medição correspondeu a 100\% de incidência. pressão de saturação e a pressão atual de vapor, visando à obtenção do déficit de pressão de vapor (diferença entre a pressão de saturação e a pressão atual de vapor) segundo as equações apresentadas por PEREIRA et al. (1997).

Para as transmissividades de RFA, foi realizada a análise de variância e as médias foram comparadas por meio da probabilidade da diferença entre elas (teste t), sendo adotado $1 \%$ de probabilidade. As médias dos dados diários dos elementos temperatura do ar (valores máximos e mínimos e médios) e do déficit de pressão de vapor foram submetidos ao teste t para médias com variâncias equivalentes, sendo adotado $1 \%$ de probabilidade, para detectar diferenças entre os pontos amostrais. 


\section{RESULTADOS E DISCUSSÃO}

Os resultados da transmissividade à radiação RFA (Tabela 1) mostram que as plantas de macadâmia, utilizadas no sistema de cultivo arborizado, promoveram uma atenuação desta até a altura das plantas de café, e foram encontradas diferenças significativas quando comparados os vários pontos amostrais dentro do sistema arborizado. Não ocorreram diferenças significativas na transmissividade entre as épocas de amostragem e interação entre épocas de amostragem e tratamentos.

A variação da transmissividade da RFA nos diferentes pontos amostrais do cultivo arborizado está relacionada com a orientação das linhas de macadâmia e o movimento aparente do sol, fazendo com que a linha de café representada pela posição ARB 2,5 SO apresentasse o menor valor de transmissividade (média de $17,3 \%$ considerando as duas amostragens), seguida pelas posições ARB 2,5 NE (69,6\%) e ARB 5,0 SO (72,4\%), que não diferiram pelo teste $t$ entre si. O ponto de amostragem ARB 5,0 NE apresentou média de 87,9\% de transmissividade, significativamente superior aos demais pontos.

A descontinuidade de cobertura vegetal em sistemas arborizados causando diferenças na transmissividade de radiação solar em diferentes pontos de cultivo de café arborizado também foi constatada por FARFAN-VALENCIA et al. (2003), na Colômbia, e PEZZOPANE et al. (2005), em um sistema consorciado de cafeeiro com banana Prata Anã, em que foram constatadas variações de 35 a $94 \%$ na transmissividade da radiação solar global. BLACK \& ONG (2000) relatam que, em cultivos arborizados de

Tabela 1 - Transmissividade da RFA (relação entre a RFA sobre as plantas de café no cultivo arborizado e a RFA externa) em quatro tratamentos, em um sistema de café arborizado com macadâmia, em São Mateus, ES, no dia 13/09/2008 e 10/02/2009.

Transmissividade média da RFA \pm Erro padrão

\begin{tabular}{lccc} 
Posição & \multicolumn{2}{c}{ Data de amostragem } & Média \\
& $13 / 09 / 2008$ & $10 / 02 / 2009$ & \\
\hline ARB 2,5 SO & $17,7 \pm 9,8$ & $17,0 \pm 5,68$ & $17,3 \pm 5,28 \mathrm{C}$ \\
ARB 5,0 SO & $74,1 \pm 6,87$ & $70,8 \pm 4,27$ & $72,4 \pm 3,80 \mathrm{~B}$ \\
ARB 5,0 NE & $88,7 \pm 1,36$ & $87,2 \pm 1,52$ & $87,9 \pm 0,98 \mathrm{~A}$ \\
ARB 2,5 NE & $78,1 \pm 6,04$ & $61,1 \pm 7,92$ & $69,6 \pm 5,62 \mathrm{~B}$ \\
Média & $64,6 \pm 7,75$ & $59,0 \pm 7,13$ & \\
\hline
\end{tabular}

Médias não seguidas da mesma letra maiúscula na coluna e da mesma letra minúscula na linha diferem entre si pelo teste $\mathrm{t}$ (P $>0,051 \%)$. café, a transmissividade da radiação solar está relacionada com a arquitetura da planta utilizada no sombreamento e o arranjo espacial utilizado.

O sombreamento em cultivos arborizados de café em regiões tropicais deve cobrir cerca de $20 \%$ da superfície, e excesso de sombreamento pode ser prejudicial à produção dos cafeeiros (DAMATTA, 2004). Nesse sentido, é de se esperar que os cafeeiros situados nas linhas contíguas àquelas de macadâmia apresentem problemas em relação à produtividade de grãos, pois, quando observada a transmissividade de radiação nessas linhas, verifica-se que sempre foi abaixo de $20 \%$, especialmente a linha de café voltada para o ponto cardeal sudoeste (ARB 2,0 SO).

Em todo o período de amostragem, a velocidade média do vento foi de $0,58 \mathrm{~m} \mathrm{~s}^{-1}$ no cultivo a pleno sol, e $0,14 \mathrm{~m} \mathrm{~s}^{-1}$ no cultivo arborizado (médias dos dois sensores), com redução média de $72 \%$ (Figura 2). A máxima velocidade foi de $9,57 \mathrm{~m} \mathrm{~s}^{-1}$ na cultura a plano sol, no dia 03/01/2009. No mesmo dia, a velocidade máxima no cultivo arborizado foi de $4,4 \mathrm{~m} \mathrm{~s}^{-1}$. Para a cultura do café, a redução da velocidade do vento promovida pela utilização de arborização é um dos efeitos mais benéficos dessa prática (BRENNER, 1996).

Os valores médios de temperatura máxima, média e mínima do ar, além do déficit de pressão de vapor para o período entre 7-10h, 10-14h e 14-18h para o sistema de produção de café a pleno sol e o arborizado com macadâmia estão apresentados na tabela 2 .

Os maiores valores médios de temperatura máxima do ar ocorreram na posição ARB 5,0 NE e no cultivo pleno sol (PS), 32,5 e $32,2^{\circ} \mathrm{C}$, respectivamente (Tabela 1). As medidas realizadas na posição ARB 2,5 SO apresentaram os menores valores de temperatura máxima com média de $30,0^{\circ} \mathrm{C}$, diferindo-se, pelo teste $\mathrm{t}$, dos demais pontos de amostragem. Para a temperatura mínima do ar, as diferenças entre as posições de medida foram menos evidentes, não sendo encontradas diferenças estatísticas entre os pontos de medida. Com relação à temperatura média, o cultivo a pleno sol apresentou os maiores valores $\left(24,9^{\circ} \mathrm{C}\right)$, seguido pelo ponto de medida ARB 5,0 NE $\left(24,7^{\circ} \mathrm{C}\right)$ e ARB 2,5 SO do cultivo arborizado $\left(24,4^{\circ} \mathrm{C}\right)$, sendo encontrada diferença estatística entre PS e ARB 2,5 SO.

Na figura 3, são apresentadas as médias horárias da temperatura, da umidade relativa e do déficit de pressão de vapor do ar, de novembro de 2008 a junho de 2009, em cultivo de café a pleno sol e em diferentes pontos amostrais de cultivo café arborizado com macadâmia. Em relação à temperatura do ar, os maiores efeitos da arborização ocorreram em período diurno, o que proporcionou maiores alterações nas temperaturas máximas do que nas mínimas (Tabela 1). 


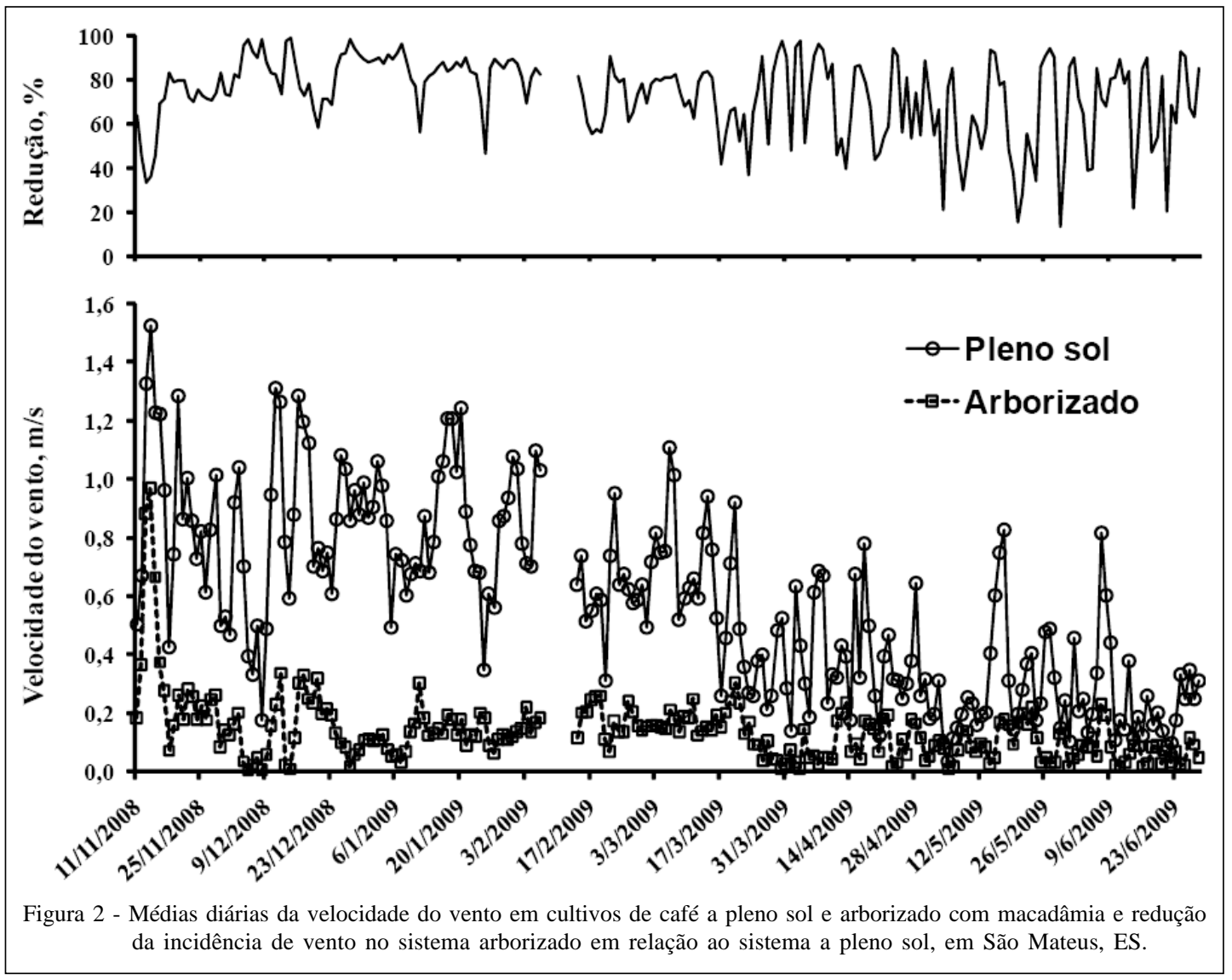

A variação das curvas mostra que, no período diurno, os menores valores de temperaturas do ar foram obtidos na posição ARB 2,5 SO, refletindo menores valores de máxima (Tabela 2). A posição ARB 5,0 NE e o cultivo a pleno sol apresentaram variações semelhantes nas horas mais quentes do dias, porém com maiores valores de temperatura do ar no cultivo a pleno sol nas primeiras horas da manhã e no final da tarde.

O maior aquecimento do ar no ponto central do cultivo arborizado (ARB 5,0 NE) em relação ao cultivo a pleno sol, com maiores valores de temperatura máxima, pode estar associado à menor movimentação do ar por

Tabela 2 - Médias diárias da temperatura do ar máxima, mínima e média $\left({ }^{\circ} \mathrm{C}\right)$ e déficit de pressão de vapor (DPV) de novembro de 2008 a junho de 2009, em cultivo de café a pleno sol (PS) e arborizado com macadâmia (ARB), em São Mateus, ES.

\begin{tabular}{|c|c|c|c|c|c|c|}
\hline \multirow{2}{*}{ Variável } & \multirow{2}{*}{$\begin{array}{l}\text { Pleno Sol } \\
\text { (PS) }\end{array}$} & \multicolumn{2}{|c|}{----------Arborizado---------- } & \multirow[b]{2}{*}{$\begin{array}{c}\text { Pleno Sol - ARB 2,5 } \\
\text { SO }\end{array}$} & \multirow[b]{2}{*}{$\begin{array}{c}\text { Pleno Sol - ARB 5,0 } \\
\text { NE }\end{array}$} & \multirow[b]{2}{*}{$\begin{array}{l}\text { ARB 2,5 SO } \\
\text { ARB5,0 NE }\end{array}$} \\
\hline & & ARB 2,5 SO & ARB 5,0 NE & & & \\
\hline $\begin{array}{l}\text { Temperatura } \\
\text { máxima }\end{array}$ & 32,2 & 30,0 & 32,5 & $8,36 * *$ & $0,73 \mathrm{~ns}$ & $8,38 * *$ \\
\hline $\begin{array}{l}\text { Temperatura } \\
\text { mínima }\end{array}$ & 20,5 & 20,7 & 20,5 & $0,99 \mathrm{~ns}$ & $0,27 \mathrm{~ns}$ & $1,30 \mathrm{~ns}$ \\
\hline $\begin{array}{l}\text { Temperatura } \\
\text { média }\end{array}$ & 24,9 & 24,4 & 24,7 & $2,77 * *$ & $0,97 \mathrm{~ns}$ & $1,75 \mathrm{~ns}$ \\
\hline DPV 7-10 horas & 0,73 & 0,52 & 0,62 & $8,89 * *$ & $3,98 * *$ & $3,76 * *$ \\
\hline DPV 10-14 horas & 1,72 & 1,38 & 1,73 & $5,77 * *$ & $0,20 \mathrm{~ns}$ & $5,55 * *$ \\
\hline DPV 14-18 horas & 1,15 & 1,03 & 1,10 & $2,80 * *$ & $1,11 \mathrm{~ns}$ & $1,66 \mathrm{~ns}$ \\
\hline
\end{tabular}

ns Não significativo; ** Significativo a $1 \%$ de probabilidade. 


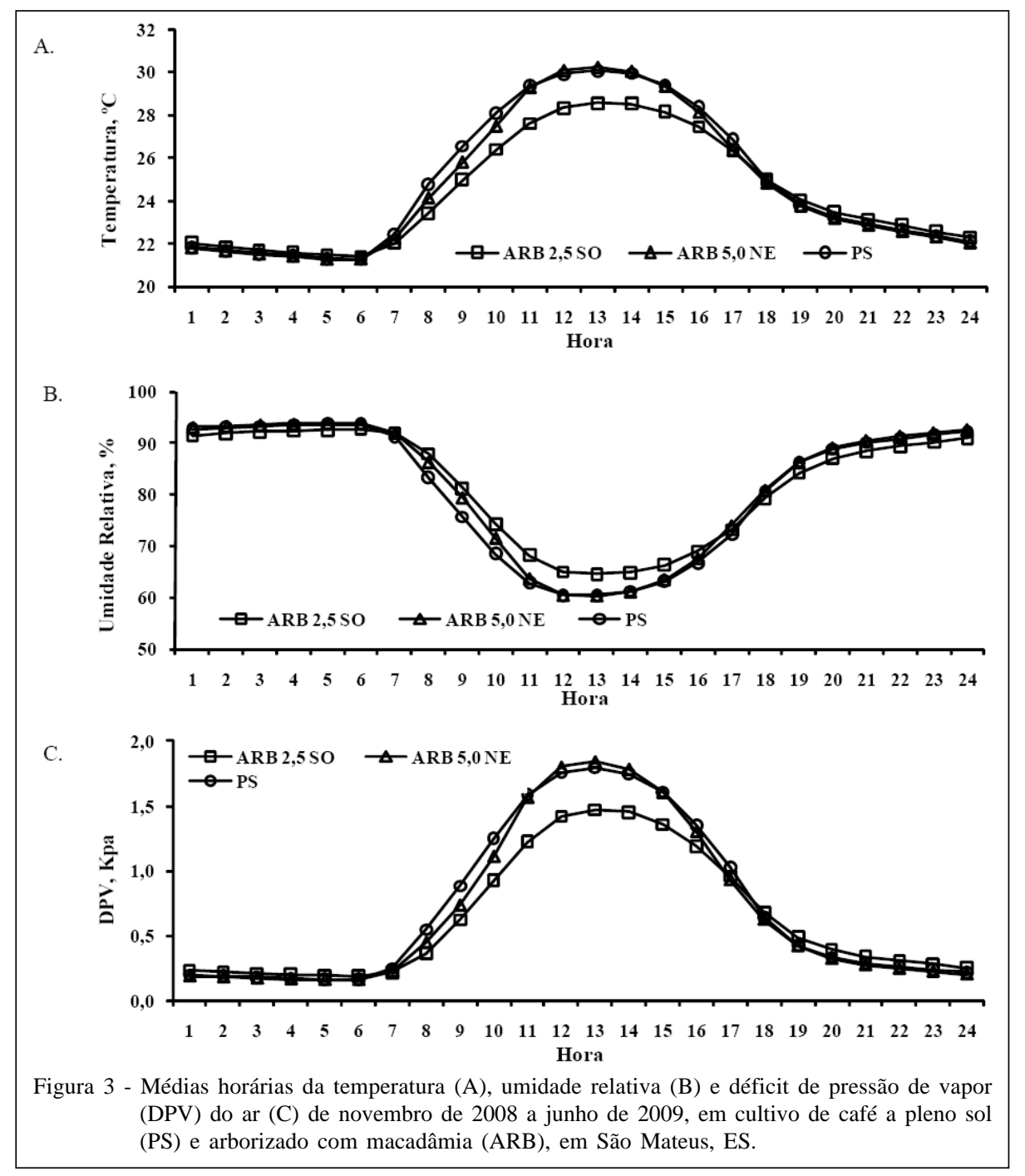

efeito de quebra-vento (Figura 2), assim como constatado por BRENNER (1996) e PEZZOPANE et al. (2007), apesar desse ponto apresentar, nas amostragens de RFA, pouco mais de $10 \%$ de atenuação promovida pelas árvores de macadâmia (Tabela 1).

A variação diária da umidade relativa média do ar se mostrou inversa à temperatura do ar (Figura 3). $\mathrm{O}$ déficit de saturação de vapor d'água apresentou diferenças mais distintas entre os pontos de leitura do que a umidade relativa do ar. No período entre 10-14h (Tabela 2), o déficit de saturação médio foi de $1,73 \mathrm{KPa}$ na posição ARB 5,0 NE, 1,72KPa no cultivo a pleno sol e 1,38KPa na posição de amostragem ARB 2,5 SO, que diferiu estatisticamente dos demais pontos. A partir da variação do déficit no período da manhã (7-10h) e da tarde (14-18h), verifica-se que os maiores valores encontrados foram no cultivo a pleno sol (Tabela 2), com diferenças estatísticas para os pontos de leitura no cultivo arborizado, no período da manhã, e apenas para ARB 2,5 SO, no período da tarde.

Menores valores de déficit de saturação de vapor em sistemas arborizados, como foi o caso da comparação entre PS e ARB 2,5 SO neste trabalho, também foram encontrados por BARRADAS \& FANJUL (1986) e PEZZOPANE et al. (2007). Os autores atribuíram esses resultados aos menores valores de temperatura do ar no período diurno, o que, neste trabalho, foi identificado principalmente no período da manhã, e também pela interceptação da radiação incidente sobre os cafeeiros arborizados, fato também verificado nesta pesquisa, principalmente no ponto próximo ao renque de macadâmias.

\section{CONCLUSÕES}

A presença de renques de macadâmia modifica o microclima, diminuindo a incidência de 
radiação fotossinteticamente ativa sobre as plantas de café e causando redução na incidência do vento. $\mathrm{O}$ cultivo arborizado provoca ainda alterações no regime térmico e de umidade relativa do ar, com maior efeito sobre os valores diurnos e no ponto de amostragem próximo ao renque de macadâmia.

\section{AGRADECIMENTO}

Os autores agradecem ao Conselho Nacional de Desenvolvimento Científico e Tecnológico (CNPq), pela concessão de bolsa e auxílio financeiro.

\section{REFERÊNCIAS}

BARRADAS, V.L.; FANJUL, L. Microclimatic characterization of shaded and apen-grow coffee (Coffea arabica L.) plantations in Mexico. Agricultural and Forest Meteorology, v.38, p.101-112, 1986

BLACK, C.; ONG, C. Utilizations of light and water in tropical agriculture. Agricultural and Forest Meteorology, v.104, n.1, p.25-47, 2000.

BRENNER, A.J. Microclimatic modifications in agroforestry. In: ONG, C.K.; HUXLEY, P. (Ed.). Tree-crop interactions A physiological approach. Cambridge: University, 1996. Cap.5, p.159-188.

CARAMORI, P.H. et al. Coffee shade with Mimosa scabrella Benth. for frost protection in southern Brazil. Agroforestry Systems, v.33, p.205-214, 1996.

DAMATTA, F.M. Ecophysiological constraints on the production of shaded and unshaded coffee: a review. Field Crops Research, v.86, p.99-114, 2004. Disponível em: <http:/ /dx.doi.org/10.1016/j.fcr.2003.09.001>. Acesso em: 01 out. 2009. doi: 10.1016/j.fcr.2003.09.001.
FARFAN-VALENCIA, F. et al. Deasarrollo de una metodologia para medir sombrio en sistemas agroflorestales com café. Cenicafé, v.54, n.1, p.24-34, 2003.

FAZUOLI, L.C. et al. Aquecimento global, mudanças climáticas e a cafeicultura paulista. O Agronômico, v.59, n.1, p.19-20, 2007.

FERRÃO, R.G. et al. Café conilon. Vitoria, ES: Incaper, 2007a. 702p.

IPCC Assessment Report, 4., 2007, Valencia, Spain. Climate change 2007: the physical science basis: summary for policymakers. [Genebra]: IPCC, 2007a. 1.8p. A report of Working Group I of the Intergovernmental Panel on Climate Change. Disponível em: <http://www.ipcc.ch>. Acesso em: 01 out. 2009.

PEREIRA, A.R. et al. Evapotranspiração. Piracicaba: FEALQ, 1997. 183p.

PEZZOPANE, J.R.M. et al. Caracterização microclimática em cultivo consorciado café/coqueiro-anão verde. Revista Brasileira de Agrometeorologia, v.1, n.2, p.293-302, 2003.

PEZZOPANE, J.R.M. et al. Radiação solar e saldo de radiação em cultivo de café a pleno sol e consorciado com banana 'Prata Anã'. Bragantia, v.64, p.487-499, 2005. Disponível em: <http://dx.doi.org/10.1590/s0006-87052005000300019>. Acesso em: 01 out. 2009. doi: 0006-87052005000300019.

PEZZOPANE, J.R.M. et al. Caracterização microclimática em cultivo consorciado café/banana. Revista Brasileira de Engenharia Agrícola e Ambiental (Online), v.11, p.256264, 2007. Disponível em: <http://dx.doi.org/10.1590/S141543662007000300003>. Acesso em: 01 out. 2009. doi: $10.1590 / \mathrm{S} 1415-43662007000300003$.

VAAST, P. et al. Fruit thinning and shade improve bean characteristics and beverage quality of coffee (Coffea arabica L.) under optimal conditions. Journal of the Science of Food and Agriculture, v.86, p.197-204, 2006. 